\title{
The Arab Spring and Its Impact on the Concept of Political Participation Among Jordanian University Students
}

\author{
Ahmed Hani Al-Katawneh ${ }^{1}$, Abdul Raouf Al Yamani ${ }^{2} \&$ Ghazi Al-Atnah ${ }^{3}$ \\ ${ }^{1}$ Isra University, Amman, Jordan \\ Correspondence: Ahmed Hani Al-Katawneh. E-mail: morganiteinstitute@yahoo.com
}

Received: June 27, 2020

Accepted: July 30, $2020 \quad$ Online Published: November 30, 2020

doi:10.5539/ass.v16n12p27

URL: https://doi.org/10.5539/ass.v16n12p27

\begin{abstract}
The current study aimed to reveal the impact of the Arab Spring on the concept of political participation among Jordanian university students (Isra University as a model), with different variables (gender, age, and school year), the researchers used the descriptive analytical approach, as a questionnaire was developed for this purpose after reviewing the theoretical literature in this field, and it was applied on a sample of (192) male and female students from Al-Isra University in the second semester of the academic year 2019. By using appropriate statistical analyzes, the results of the study revealed that the effect of the Arab Spring on the concept of political participation among Jordanian university students came with an average degree, as the results showed that there were no statistically significant differences for the impact of the Arab Spring on the concept of political participation among Jordanian university students due to gender and age variables, while a statistically significant difference was observed between the arithmetic averages of the effect of the Arab Spring on the concept of political participation among Jordanian university students due to the variable of the school year in favor of the first, second and third years when compared to the fourth and fifth years.
\end{abstract}

Keywords: Arab Spring, political participation, Al-Isra University

\section{Introduction}

Over the past eight years since the beginning of 2011, the Arab region has witnessed widespread popular protests against Arab regimes and their policies as a result of the absence of democracy, social justice, freedom, a decent life, high unemployment, poverty, and many other factors, this has affected the political stability of these countries and made them witness the beginnings of broad popular uprisings rejecting these policies, known as the (Arab Spring) revolutions, they started from Tunisia - the center of the Arab Spring - at the beginning of 2011 and then stormed and are still raging in most countries of the Arab world until now (Bradley, 2013).

\section{Arab Spring}

The Arab region remained the only one of the world with a special exception that was not affected by the waves of democratic transitions that affected a number of countries such as Latin America in the seventies, and the countries of Central and Eastern Europe, Southeast Asia and Africa in the eighties and nineties, this is because Arab culture has a patriarchal nature that reinforces the values of hearing, obedience and centralization of power and prevents the escalation of tendencies and individual values that represent the cultural basis for the emergence of the idea of human and civil and political rights, that is why the Arab countries have remained since their establishment under the influence of authoritarian or republican authoritarian regimes until the Tunisian revolution in 2011 (the spark of the Arab Spring) came to negate the premise of the Arab exception to the transition to democracy and the masses then went out in most Arab countries to demand freedoms, democracy and social justice (Shehata, 2015).

It is believed that the Arab Spring revolutions have resulted in all the countries of the Arab Spring as a result of dissatisfaction with the policies of regimes and governments, violations of human rights, corruption, economic decline, poverty, unemployment, etc. And that the main driver of these revolutions is the principle of restoring dignity to the Arab person. Consequently, the youth refused to accept this situation, which resulted in pressures that contributed to the eruptions in the Arab region, despite the different ways of expressing it and its demands. Still, transformations accompanied it in culture and political awareness, and political concepts emerged on the scene that was inactive before, such as freedom, social justice, equality, and political participation (Al-Zamili, 
2013).

The term Arab Spring dates back to the revolutions that took place in 1848, referred to as the (Spring of Nations), and Western media suggested it as a moment of remembrance of the spring (Bazag) in 1968 (Perrin, 2013), and (Al-Sawaeer, 2017).

In the Arab world, the term Arab Spring was called for revolutions and protests that started since the beginning of 2011 affected by the Tunisian revolution, which erupted in protest against the poor living conditions after Bouazizi's burning, which then toppled Tunisian President Zine El Abidine Ben Ali. The protest movements escalated despite the different ways of expressing them to other Arab countries such as Egypt, Libya, Yemen, Algeria, Sudan, Syria, Jordan, etc., and the relative success that these revolutions achieved contributed to this spread (Ayasarah, 2016), (Khurma, 2014).

Jordan was not spared from these protests after Tunisia rang the bells of the Arab Spring, this immediately echoed in Jordan, as daily workers and a number of young activists organized popular rallies in the Theban Brigade in 2011, and then workers organized another rally in the center of the capital, Amman, in the same year carrying slogans: bread, freedom, and social justice, but they did not reach the level of revolutions, but rather were called (mobility), like the movement of Theban, the movement of the Karak, the free movement of "Ahrar Al Tafila" and others.

\section{Causes of the Arab Spring}

There are a set of internal and external factors that have led, directly or indirectly, to the revolutions of the Arab Spring:

1. Internal reasons:

a. Social and economic reasons: Most of the people in the Middle East live under patronage and tribalism (Al-Arabi, 2012), and that most Middle Eastern countries suffer from economic backwardness that depends in most cases on oil imports, tourism or foreign aid, while real development is absent due to the high population and the lack of cadres, all of which led to a decrease in the level of per capita income and the emergence of poverty and unemployment, especially among educated youth, the internal conditions prevailing in the countries of the Arab world generated a state of popular congestion that sparked the revolutions (Ahmed, 2013).

b. Political reasons: Most of the systems of Middle Eastern countries are authoritarian regimes in which there are no manifestations of political pluralism, the peaceful transfer of power, freedom of expression, the media, and the absence of integrity and agreement in the elections, all of which contributed to the outbreak of the Arab revolutions (Rahma, 2012).

2. External reasons:

a. American Intervention in Arab Affairs: After the events of September 2001, the United States linked terrorism and the absence of freedoms in the Arab world, as Arab countries came under American pressure to undertake political, religious, social, and economic reforms and to adjust curricula (Al-Asadi \& Shaboot, 2018).

b. Regional states' influence escalated: As the Arab countries witnessed a remarkable escalation in the influence of some regional countries such as Iran and Turkey, it began to affect significantly Arab affairs in terms of providing support to some systems and movements, as Iran supported the Syrian regime, Hezbollah in Lebanon and Hamas in Palestine and the Houthis in Yemen (Al-Asadi \& Al-Shaboot, 2018).

c. The revolution in the field of media and communications: Social media and alternative media (satellite channels, the Internet and mobile phones) have contributed significantly to breaking the barrier of fear and Arab media silence, as protest movements have given the ability to communicate their voice to the world (Al-Shalabi, 2000).

These networks also facilitated the means of communication between all segments of one society, where young people were able in a short period to mobilize their energies and agree on the place and time to carry out these protests and pushed the youth to establish new patterns of political participation that enabled them to overcome many of the restrictions imposed by the Arab regimes on freedom of expression (Abu Bakr, 2013).

\section{Political Participation}

The concept of political participation is considered one of the political concepts that imposed itself after the Arab 
Spring revolutions in a number of Arab countries in response to the desire of their peoples for the right to equality and recognition of the other as equals with the counterpart regardless of race, religion or gender, desiring to allow everyone to participate through democratic mechanisms, considering that they have social, economic and political rights that must be protected by the constitution.

The concept of political participation in its simplest definitions indicates that it is a political activity that symbolizes the contribution of ordinary citizens and their role within the political system with the intent to influence the government decision-making process, whether this activity is individual or collective, organized or spontaneous, legal or illegal (Al-Beige, 1997). Political participation takes many forms, including nomination and voting, and participation in election campaigns (Al-Salwi, 2007). Also, attending political conferences, joining party membership, and running for public office (Hamdi, 1993). Al-Sayyed (1996) believes that participation in peaceful protests, marches, and demonstrations to push politicians to make certain decisions or withdraw from other decisions is also a form of political participation. However, regardless of the forms and forms of political participation, they aim at the end of the day to develop a sense of responsibility, initiative, and belonging to citizens and raise their ability to influence political decisions and guidance. The concept of political participation is one of the essential concepts that have attracted the attention of many thinkers and politicians as the basis of the democratic act because many other political concepts whose success depends on the availability of political participation to citizens, also, the concept of political participation is not just a slogan for a country or a feature of a society, but rather a philosophy that must be believed in and work to take legal steps and provide intellectual means in order to achieve this process on the ground (Mashti, 2010).

Young people are considered the main pillar for achieving societal and political development. Automatic political participation is considered to activate the citizen's role in managing public affairs and is one of the tools of democratic behavior that aims to highlight the positive of citizens dealing with public affairs.

What is worth noting is that the degrees of political participation are related to the nature of the political structures of the systems, the extent to which they are suitable for the citizens 'political activities, the extent to which their real contribution to the political process is permitted, and the availability of political institutions able to absorb the citizens' political activities (Serag El-Din, 2008).

\subsection{The Study Problem and its Questions}

The current study's problem is determined in revealing the extent of Jordanian youth's participation in political decision-making after the Arab Spring revolutions and the resulting youth's moves towards more democracy, which exceeded the extent of protests and demonstrations to demand the right to political participation in shaping the general policy of the state. Accordingly, the current study aimed to explain the Arab Spring and its impact on the concept of political participation among Jordanian university students (Al-Isra University as an example), by answering the following questions:

1. To what extent does the Arab Spring affect the concept of political participation among Jordanian university students (Al-Isra University as a model)?

2. Are there statistically significant differences in the Arab Spring's effect on the concept of political participation among Jordanian university students due to the variable (gender, age, and school year)?

\subsection{The Importance of the Study}

The importance of the study stems from the following:

1. Theoretical and practical significance: where the reality of the Arab Spring and its impact on the countries of the Arab Spring need to quantitative and qualitative study in view of the importance of what happened and is still taking place in the Arab region of revolutions and protests and the changes that people have created on concepts such as freedom, political participation, and social justice ... Etc., significantly since the impact of the Arab Spring has affected Jordan, therefore, it is possible for this study, given the theoretical basis for its subject in the academic field, to add to theoretical literature in this field, and it may also add recommendations that benefit those interested and specialists in this field.

2. The importance of the current study stems from the importance of the target group, which is the youth group, where they constitute the largest category of those responsible for these revolutions since most of the Arab Spring revolutions were bearing the slogan (youth of change)

\subsection{Procedural Definitions of Study Terms}

Political participation: is the set of activities, events, and behaviors expected of citizens, such as expressing an opinion on a national issue, affiliation with political parties, participating in political meetings, marching in 
peaceful marches, entering into discussions with others, attending and inviting political conferences, and communicating with political officials, and running for public office and others (Shuweihat, 2013).

The Arab Spring: A revolutionary wave of violent or non-violent demonstrations and protests, and the riots and civil wars that pervaded the countries of the Arab world that began in Tunisia in late 2010 and spread as a wave of protests to a large number of Arab countries (Al-Asadi \& Al-Shaboot, 2018).

Al-Isra University: It is one of the private Jordanian universities established in 1991 and is located in the Tunaib area on the way to Queen Alia International Airport south of the capital, Amman.

\subsection{The Limits of the Study}

The current study is determined by the following:

1. Human and spatial limits: The study is determined by the population and its specifications, as the study was limited to a sample of Al-Isra University students who are studying regularly, from the age of less than 20 years to the age of 23 years.

2. Time limits: The study is determined by the time in which the study was conducted and applied, which is the second quarter of 2019.

3. Objective limits: The current study was limited to the identification of the Arab Spring and its impact on the concept of political participation only, according to the viewpoint of students and their relationship to their gender, age, and school year, as the study is determined by a tool that researchers verified its validity and reliability and its relevance to the sample and the objectives of the study.

\section{Previous Studies}

Al-Azzam (2003) conducted a study to identify the attitudes of Jordanians towards political parties, which consisted of 1487 individuals aged 18 years and over from the governorate of Irbid. The study results showed that there are negative trends towards participation in political parties and that university students do not tend to participate in political parties in general.

Banducci and Karp (2008) conducted a study aimed at comparing males and females in representing political participation; the study used data related to elections at the national level in 35 countries. The results of the study showed that there are statistically significant differences between males and females regarding political participation in favor of males, and the study tried to identify obstacles preventing females from political participation.

Al-Shami (2011) carried out a study aimed at knowing the level of participation of Palestinian university youth, the study sample consisted of (469) male and female students from Al-Aqsa University students, and the researcher used a scale prepared for this purpose, the results of the study showed that the level of political participation of Palestinian university youth came moderate, and that the domain of political activity came first, followed by the domain of political knowledge and then the domain of political interest, and that more than half of the Palestinian university youth was politically active compared to a politically inactive third. The results also showed a relationship between basic participation and variables such as gender, family income, organizational affiliation, type of college, and marital status. There is no relationship between political participation and the place of residence. The results also showed that partisan affiliation is the best form of political involvement. Some students refrain from Political participation because some parties work for its benefits and not for the public benefit, and affiliation with a party other than the government causes them problems.

In a study of Shaefer and passions (2011) aimed at identifying the impact of the events of January 25, 2011, in Cairo on political awareness and political participation of the people of Cairo, the sample consisted of Cairo residents who are between the ages of 18-30 years, the questionnaire prepared for this purpose was used, and the results of the study indicated that the events had a positive impact as the political awareness of the people increased and their political participation increased.

Maatouq (2012) conducted a study aimed at revealing the impact of political factors on the movements for change in the Arab world; the results showed that the most prominent of these factors were the absence of the concept of the peaceful transfer of power and the path towards inheriting power and the absence of party pluralism that guarantees the active political participation of all political parties, in addition to the lack of free and fair elections.

Omaima (2012) conducted a study aimed at identifying political and administrative corruption as one of the causes of the Arab revolutions. The results of the study showed that political systems are the most factors that have led to the spread of corruption, especially those systems that are distinguished by the rule alone from the 
rest of civil society and which are dominated by a dictatorial and authoritarian nature and it prevents freedom of opinion and accountability and activating the role of censorship.

Jweihat and Al-Khawaldeh (2013) conducted a study aimed at identifying the trends of university students towards political participation in Jordan, the study sample consisted of (515) male and female students who were chosen randomly, and the results of the study showed that the attitudes of students towards political participation came moderately for the most critical reasons low awareness of the importance of political participation.

Al-Sulehat (2013) conducted a study aimed at knowing the repercussions of the Arab Spring revolutions on political awareness among Jordanian university students in the central region, applied to a sample of Jordanian university students in the central area using a questionnaire prepared for this purpose, the results of the study showed that the repercussions of the Arab Spring revolutions on the level of political awareness among Jordanian university students in the central region came high. The gender and college variables did not have a statistically significant effect, whereas the university type variable had a statistically significant impact in favor of government universities.

In a study by Korotayev et al., (2014) that aimed to quantify the events of the Arab Spring and the factors that affect social and political stability in the countries of the Arab Spring, the results of the study showed that the destabilization of social and political stability in the countries of the Arab Spring is due to a set of factors. The results also showed that the most important factors that led to the reduction of this destabilization are the government's ability to reduce tensions and the presence of immunity for internal conflicts. The study also stressed the need to discuss the possibility of applying the developed model to destabilize social and political stability to predict future unrest.

Ayasrah (2016) carried out a study that aimed to reveal the main factors behind the outbreak of protests and revolutions in the countries of the Arab Spring and to identify the differences between Arab countries with regard to variables of the study; it was conducted on all Arab countries, the results of the study showed the presence of two factors around which the study variables had a clear impact In the outbreak of revolutions in the Arab world, the results also showed that there are statistically significant differences between Arab countries concerning the variables of the study, which are considered weak when compared with other countries.

The study of Al-Sawaeer (2017) aimed at knowing the orientations of the Jordanian foreign policy towards the crises of the Arab Spring during the period between (2011-2017); the study adopted the descriptive analytical approach in explaining the nature and causes of the outbreak of the Arab Spring revolutions and Jordanian positions towards them. The study results showed that the Arab Spring revolutions had affected the repercussions of the Jordanian foreign policy, so the Jordanian positions came with the crises of the Arab Spring, consistent with national interests and support for stability in the Arab Spring countries.

\section{Comment on Previous Studies}

Through reviewing the previous studies, the following is noted:

- Most of the Arab and foreign studies did not pay much attention to the impact of the Arab revolutions on political awareness and political concepts. Rather, they were most interested in revealing the reasons and motives that led to the emergence of revolutions in the Arab world, such as the study of Ayasrah (2016), Omaima (2012), and the study of Maatouk (2012).

- Some foreign studies concerned the differences between males and females in the level of political participation and the identification of obstacles that prevent effective female participation.

- Jordanian studies are few in this topic, and if they exist, they focus on political parties and the attitudes of Jordanians towards participation in them, such as the study of Al-Shami (2011) and Al-Azzam (2003), or on investigating the students 'attitudes towards political participation in general, such as the study of Shuweihat and Al-Khawaldah (2013). Some were concerned with the impact of the repercussions of the Arab Spring revolutions on Jordanian foreign policy with the Arab Spring countries, such as the study of Al-Sawaeer (2017), and others were interested in studying the repercussions of the Arab Spring revolutions on political awareness in general, such as the Sulaihat study (2013).

We note that previous studies have focused on other issues related to the Arab Spring revolutions and their results and on various Arab environments, such as the reasons and factors leading to these revolutions or the implications of these revolutions on political awareness in general and not on specific political concepts such as political participation, where there is no study - according to the knowledge of the researchers - that dealt with the Arab Spring and its impact on the concept of political participation among Jordanian university students according to the variables (gender, age and school year) and therefore, based on the different environments of 
previous studies, their samples and timing, this is what distinguishes the current study from others in that it is a field study that dealt with an important segment of Jordanian society, which is the educated youth segment and is a significant time.

\section{Method and Procedures}

\subsection{Study Approach}

The researchers used the descriptive and analytical method, as it is appropriate to the study's nature, through which the phenomenon is described and its general framework determined through data collection, classification, analysis, and access to facts.

\subsection{The Study Population and Its Sample}

The study population is composed of all students of Al-Isra University in Amman and those who are engaging in it. A representative sample of the University of Isra students was chosen, consisting of (192) male and female students, taking into account the variables of age, gender, and school year, where the study tool was distributed.

Table 1 represents the frequencies and percentages of the study sample

Table 1. Distribution of study sample individuals according to the study variables

\begin{tabular}{|c|c|c|c|c|}
\hline $\mathrm{N}$ & Variable & Level & Number & Percentage \\
\hline \multirow{3}{*}{1} & \multirow{3}{*}{ Gender } & Male & 86 & $\% 44.8$ \\
\hline & & Female & 106 & $\% 55.2$ \\
\hline & & Total & $192 \quad 18$ & $\% 100$ \\
\hline \multirow{4}{*}{2} & \multirow{4}{*}{ Age } & Less than 20 years & 50 & $\% 26$ \\
\hline & & From 20 to 23 years old & 100 & $\% 52.1$ \\
\hline & & Over 23 years old & 42 & $\% 21.9$ \\
\hline & & Total & 192 & $\% 100$ \\
\hline \multirow{6}{*}{3} & \multirow{6}{*}{ Academic year } & First-year & 75 & $\% 39.1$ \\
\hline & & Second-year & 51 & $\% 26.6$ \\
\hline & & Third-year & 25 & $\% 13$ \\
\hline & & Fourth-year & 34 & $\% 17.7$ \\
\hline & & Fifth-year & 7 & $\% 3.6$ \\
\hline & & Total & 192 & $\% 100$ \\
\hline
\end{tabular}

\subsection{The Study Tool}

The study tool was prepared after reviewing the theoretical literature in this field, and the light of previous studies, experts and specialists in this field, where a questionnaire was constructed for this purpose and quintet-Likert scale was used where the answer to the questionnaire items ranged between I strongly agree (5 points), I agree (4 points), and neutral ( 3 points), disagree ( 2 points), and strongly disagree (1 point).

3.3.1 Validity and Reliability of the Tool

Researchers confirmed the validity of the tool by:

- Logical validity: the questionnaire items were formulated in light of the theoretical framework and previous studies on this topic.

- The arbitrators' validity: The tool was presented to (10) arbitrators from professors, specialists, and faculty members, as the items that did not reach an agreement rate of $(80 \%)$ were excluded.

The researchers also confirmed the tool's reliability by extracting the Cronbach alpha coefficient for the Arab Spring and its effect on the concept of political participation among Jordanian university students, where it was ( 88 and 0 ); this percentage was considered appropriate for the purposes of the study.

\subsection{Study Procedures}

The researchers follow the following steps to complete the study:

1. Review the theoretical literature and previous studies in the field of study.

2. Prepare the study tool in its initial form.

3. Display the tool to the specialists. 
4. Conducting a survey study on (30) male and female students, as the tool was applied to them, the researchers confirmed the items' clarity and their suitability for use.

5. Review the tool and amend its items in light of the survey study and the opinions of specialists.

6. Ensure the validity and reliability of the tool.

7. Distribute the questionnaire to the study sample.

8. Collecting questionnaires, emptying data, and statistically processing them.

9. Extraction of results, discussion, and recommendations

\subsection{Statistical Treatments}

The results were analyzed statistically, and the following statistical treatments were used:

- Arithmetic averages for knowledge of the Arab Spring and its effect on political participation among Jordanian university students.

- $\quad(\mathrm{T})$ test to determine the differences attributed to gender.

- One-way analysis of variance to find the differences due to age and school year.

- $\quad$ L.S.D test for dimensional comparisons to find out that the differences lay in favor of five-year levels.

- Cronbach Alpha coefficient to find the reliability of the tool.

\section{The Results of the Study and Its Discussion}

Results related to the first question: What is the extent of the impact of the Arab Spring on the concept of political participation among Jordanian university students?

To answer this question, arithmetic averages and standard deviations were calculated for the extent of the impact of the Arab Spring on the concept of political participation among Jordanian university students, as shown in Table 2.

Table 2. Arithmetic averages in descending order and standard deviations of the impact of the Arab Spring on the concept of political participation among Jordanian university students

\begin{tabular}{|c|c|c|c|c|c|}
\hline Rank & $\mathrm{N}$ & Item & Mean & $\begin{array}{l}\text { Standard } \\
\text { deviation }\end{array}$ & $\begin{array}{l}\text { Degree of } \\
\text { approval }\end{array}$ \\
\hline 1 & 7 & $\begin{array}{l}\text { It increased my interest in the follow-up to the political situation in my } \\
\text { country. }\end{array}$ & 4.07 & 1.00 & High \\
\hline 2 & 15 & It increased my sense of social responsibility & 3.95 & 0.94 & High \\
\hline 3 & 6 & It corrected some of my misconceptions & 3.83 & 0.97 & High \\
\hline 4 & 14 & $\begin{array}{l}\text { It increased my confidence in the role of collective efforts in } \\
\text { decision-making }\end{array}$ & 3.83 & 1.11 & High \\
\hline 5 & 26 & It increased my interest in the political situation in my country & 3.80 & 1.10 & High \\
\hline 6 & 13 & $\begin{array}{l}\text { It increased my belief in the efforts of citizens to participate in } \\
\text { policy-making }\end{array}$ & 3.74 & 1.04 & High \\
\hline 7 & 8 & It increased my confidence in my ability to change & 3.66 & 1.03 & Moderate \\
\hline 8 & 16 & It increased my confidence in the ability of teamwork to change officials & 3.66 & 1.19 & Moderate \\
\hline 9 & 3 & It strengthened my feeling that I am equal in my rights with others & 3.60 & 1.18 & Moderate \\
\hline 10 & 27 & $\begin{array}{l}\text { It increased my belief in the ability of political participation to bring } \\
\text { about change }\end{array}$ & 3.56 & 1.16 & Moderate \\
\hline 11 & 1 & It increased my confidence in my ability to change & 3.55 & 1.11 & Moderate \\
\hline 12 & 19 & It increased the democratic atmosphere in my country & 3.52 & 1.14 & Moderate \\
\hline 13 & 9 & It made me elected the Best Member of Parliament & 3.49 & 1.30 & Moderate \\
\hline 14 & 24 & It increased people's influence on the direction of government & 3.44 & 1.10 & Moderate \\
\hline 15 & 11 & It reduced my interest in political issues & 3.38 & 1.12 & Moderate \\
\hline 16 & 2 & It made me participate in political discussions with others & 3.28 & 1.10 & Moderate \\
\hline 17 & 22 & It made me participate in political discussions with others & 3.21 & 1.18 & Moderate \\
\hline 18 & 18 & It increased my conviction that peoples' struggle leads to no result & 3.20 & 1.28 & Moderate \\
\hline
\end{tabular}




\begin{tabular}{cclccc}
\hline 19 & 12 & It increased my conviction of the inability to change & 3.18 & 1.25 & Moderate \\
20 & 4 & It made me participate in anti-corruption campaigns & 3.16 & 1.14 & Moderate \\
21 & 21 & It contributed to fighting corruption in earnest & 3.13 & 1.28 & Moderate \\
22 & 10 & It made me participate in peaceful rallies for change & 3.05 & 1.07 & Moderate \\
23 & 17 & It reduced my participation in peaceful marches & 3.04 & 1.03 & Moderate \\
24 & 20 & It contributed to reducing the rate of political participation in my country & 3.01 & 1.12 & Moderate \\
25 & 25 & It increased my participation in attending political seminars & 2.84 & 1.11 & Moderate \\
26 & 5 & It strengthened my attendance at political seminars & 2.79 & 1.02 & Moderate \\
27 & 23 & It made me join the political parties & 2.57 & 1.15 & Moderate \\
& & Total & 3.39 & 0.516 & \\
\hline
\end{tabular}

It is noted from Table 1 that the arithmetic means of the extent of the impact of the Arab Spring on the concept of political participation among Jordanian university students was (3.39), with a standard deviation (0.52), and with an average degree of approval, and the mean averages for the domain's items ranged between (2.57-4.07).

The researchers explain this result that the university students are busy in their academic achievement in this period and are not involved in political parties so that they increase their awareness and political culture and their understanding of the concept of political participation, this result was consistent with the study (Shwahat, 2013), the study (Al-Shami, 2011) and the study (Jweihan \& Al-Khawaldeh, 2013), where item (7): It increased my interest in following up the political situation in my country, came in the first rank among the study sample individuals with an average score of (4.07), a standard deviation (1.00), and a high degree of approval, the researchers explain this in the fact that the Arab Spring revolutions in their beginnings in Tunisia, Libya and Egypt have achieved apparent successes, which pushed the Jordanian youth to their deep belief in the ability to change for the better, which increased their interest in following the political situation and increased their awareness of the political reality surrounding them to improve their knowledge base on political issues surrounding them, the following items also came respectively: item (15): It increased my sense of social responsibility, came in the second rank among the individuals in the study sample with an average score of (3.95) and a standard deviation (0.94), and a high degree of approval, while item (6): It corrected some of my misconceptions, came in the third rank with a mean of (3.83) and with a standard deviation (0.97) and a high degree of approval, while item (25): It increased my participation in attending political seminars, came in the second rank with a mean of (2.84), and a standard deviation (1.11) and a moderate approval score, item (5): It strengthened my attendance at political seminars, also came in the penultimate rank, with an average score of (2.79), with a standard deviation (1.02), and a moderate degree of approval. Finally, item (23): It made me join the political parties, came last with a mean of (2.57) ), and a standard deviation (1.15) and a moderate degree of approval; the researchers explain this result in the weakness of university youth participation in political parties and affiliation with them because they do not believe in the ability of political parties to change and they consider that political parties bring them problems and troubles and that they carry slogans far from implementation and their only goal is the struggle for power more than serving the local community, and this result agreed with the study of (Al-Azzam, 2003) and partly differed with the study of (Al-Shami, 2011).

Results relating to the second question: Are there statistically significant differences at the level of significance $(\alpha=0.05)$ in the impact of the Arab Spring on the concept of political participation among Jordanian university students due to variables (gender, age, and school year)?

\section{a. Gender Variable}

To find out whether there are statistically significant differences, arithmetic averages and standard deviations were calculated, and the use of the $(\mathrm{T})$ test to reveal the significance of the differences for the impact of the Arab Spring on the concept of political participation is attributed to the gender variable, as shown in Table 2.

Table 2. Arithmetic averages, standard deviations, and (T) test results for the significance of differences for the effect of the Arab Spring on the concept of political participation among Jordanian university students due to the gender variable

\begin{tabular}{cccccccc}
\hline Variable & Levels of variable & $\mathbf{N}$ & Percentage & Standard deviation & df & “T” value & Sig \\
\hline \multirow{2}{*}{ Gender } & Male & 86 & 3.35 & 0.499 & 190 & $1.08-$ & $\mathbf{0 . 2 8 0}$ \\
& Female & $\mathbf{1 0 6}$ & $\mathbf{3 . 4 3}$ & $\mathbf{0 . 5 2 9}$ & & & \\
\hline
\end{tabular}

* Significance level: $(\alpha=0.05)$ 
It is noted from Table 2 that there are no statistically significant differences at the level of significance $(\alpha=0.05)$, so the effect of the Arab Spring on the concept of political participation among Jordanian university students is attributed to the gender variable, based on the calculated value of $t$ which reached (-1.08), and the level of significance reached (0.280).

The researchers explain that the Arab Spring revolutions strengthened the concept of political participation among both males and females alike where both sexes wish to participate in politics because Arab revolutions were launched by young men and women of both sexes and they are the main engine for it, and the prevailing conditions are a problem of concern to both sexes, and this result agreed with the study of (Al-Suleihat \& Malluh, 2013), and it differed with the study of (Banducci \& Karp, 2008).

\section{b. The Age}

To find out whether there are statistically significant differences, arithmetic averages and standard deviations were calculated to reveal the significance of the differences for the impact of the Arab Spring on the concept of political participation among Jordanian university students due to the age variable, as shown in Table 3.

Table 3. Arithmetic averages and standard deviations for students to see the effect of the Arab Spring on the concept of political participation among Jordanian university students according to the age variable

\begin{tabular}{ccccc}
\hline Variable & Age levels & N & Mean & Standard deviation \\
\hline & Less than 20 years & 50 & 3.45 & 0.35 \\
Age & From 20 to 23 years old & 100 & 3.38 & 0.57 \\
& Over 23 years old & 42 & 3.36 & 0.56 \\
& Total & 192 & 3.39 & 0.52 \\
\hline
\end{tabular}

It is noted from Table 3 that there are apparent differences between the arithmetic averages of the effect of the Arab Spring on the concept of political participation among Jordanian university students according to the age variable, and to verify the significance of the apparent differences, one way ANOVA was performed for their responses according to the age variable, as in Table 4.

Table 4. The results of the One-Way ANOVA analysis of the impact of the Arab Spring on the concept of political participation among Jordanian university students according to the age variable

\begin{tabular}{cccccc}
\hline Source of variance & Sum of squares & df & Mean of squares & F value & Sig \\
\hline Between groups & 0.212 & 2 & 0.11 & 0.40 & 0.674 \\
Within groups & 50.69 & 189 & 0.27 & & \\
Total & 50.902 & 191 & & & \\
\hline
\end{tabular}

The results of Table 4 indicate that there are no statistically significant differences at the level of significance ( $\alpha$ $=0.05$ ) of the effect of the Arab Spring on the concept of political participation among Jordanian university students according to the age variable, based on the calculated values of (0.40), and the level of significance reached (0.674). The researchers explain that all members of the study sample are of the age of adolescent youth who are pushing for change in the face of difficult conditions in the search for a better decent life to build his future and achieve his goals, especially since most of the Arab Spring revolutions were under the slogan (Youth of Change).

\section{c. Academic Year}

To find out whether there are statistically significant differences, arithmetic averages and standard deviations have been calculated to reveal the significance of the differences for the impact of the Arab Spring on the concept of political participation among Jordanian university students due to the variable of the school year, as shown in Table 5.

Table 5. Arithmetic averages and standard deviations for the effect of the Arab Spring on the concept of political participation among Jordanian university students according to the variable of the school year

\begin{tabular}{ccccc}
\hline Variable & School year levels & N & Mean & Standard deviation \\
\hline & First & 75 & 3.44 & 0.40 \\
Academic year & Second & 51 & 3.46 & 0.54 \\
& Third & 25 & 3.48 & 0.36 \\
& Fourth & 34 & 3.2 & 0.61 \\
\hline
\end{tabular}




$\begin{array}{lccc}\text { Fifth } & 7 & 3.05 & 1.00 \\ \text { Total } & 192 & 3.39 & 0.52\end{array}$

It is noted from Table 5 that there are apparent differences between the arithmetic averages of the effect of the Arab Spring on the concept of political participation among Jordanian university students according to the variable of the school year, and to verify the significance of the apparent differences, one way ANOVA was performed for their responses according to the variable of the school year, as shown in Table 6 .

Table 6. The results of the One-Way ANOVA analysis of the impact of the Arab Spring on the concept of political participation among Jordanian university students according to the variable of the school year

\begin{tabular}{cccccc}
\hline Source of variance & Sum of squares & df & Mean of squares & F value & Sig \\
\hline Between groups & 2.665 & 4 & 0.67 & 2.58 & $* 0.039$ \\
Within groups & 48.237 & 187 & 0.26 & & \\
Total & 50.902 & 191 & & & \\
\hline
\end{tabular}

It is noted from Table 6 that there are statistically significant differences at the level of significance $(\alpha=0.05)$ of the effect of the Arab Spring on the concept of political participation among Jordanian university students according to the variable of the academic year, based on the calculated values of " $F$ " and amounting to (2.58), and at a level of significance of (0.039).

To find out in favor of which of the five levels of the academic year the differences lie, a significant difference test (L.S.D) was performed for the dimensional comparisons as shown in Table 7:

Table 7. Results of the post-test (L.S.D) for comparison between the arithmetic averages in the view of Jordanian university students on the effect of the Arab Spring on the concept of political participation according to the variable of the academic year

\begin{tabular}{|c|c|c|c|c|c|c|c|c|c|c|c|}
\hline \multirow{2}{*}{$\begin{array}{c}\text { Variable } \\
\text { categories }\end{array}$} & \multirow{2}{*}{$\stackrel{\Xi}{E}$} & \multicolumn{2}{|c|}{ First } & \multicolumn{2}{|c|}{ Second } & \multicolumn{2}{|c|}{ Third } & \multicolumn{2}{|c|}{ Fourth } & \multicolumn{2}{|c|}{ Fifth } \\
\hline & & $\begin{array}{c}\text { The } \\
\text { difference }\end{array}$ & Sig & $\begin{array}{c}\text { The } \\
\text { difference }\end{array}$ & Sig & $\begin{array}{c}\text { The } \\
\text { difference }\end{array}$ & Sig & $\begin{array}{c}\text { The } \\
\text { difference }\end{array}$ & Sig & $\begin{array}{c}\text { The } \\
\text { difference }\end{array}$ & Sig \\
\hline First & 3.44 & - & - & 0.021 & 0.82 & 0.048 & 0.68 & 0.239 & $* 0.02$ & 0.382 & 0.06 \\
\hline Second & 3.46 & 0.021 & 0.82 & - & - & $0.03-$ & 0.83 & 0.26 & $* 0.02$ & 0.40 & $* 0.05$ \\
\hline Third & 3.48 & 0.048 & 0.68 & $0.03-$ & 0.83 & - & - & 0.29 & $* 0.03$ & 0.43 & *0.049 \\
\hline Fourth & 3.2 & 0.239 & $* 0.02$ & 0.26 & $* 0.02$ & 0.29 & $* 0.03$ & - & - & 0.14 & 0.498 \\
\hline Fifth & 3.05 & 0.382 & 0.06 & 0.40 & $* 0.05$ & 0.43 & $* 0.049$ & 0.14 & 0.498 & - & - \\
\hline
\end{tabular}

It is noted from Table 7 that the differences in the influence of the Arab Spring on the concept of political participation among Jordanian university students according to the variable of the academic year were in favor of students in the first, second and third year when compared to students in the fourth year, in addition to the presence of differences that were in favor of students in the second and third year when compared to Students in the fifth year. The researchers explain this result that the university students of different levels of education were affected by the concept of political participation in varying degrees as a result of the Arab Spring revolutions and that the differences came in favor of students of the first, second and third years because they fall into the stage of late adolescence and early adulthood and they are more enthusiastic and impulsive and that the fourth and fifth-year students are graduates students engaged in their graduation research.

\section{Study Recommendations}

Based on the results of the study, the following recommendations can be made:

1. To benefit from the results of the Arab Spring revolutions and the mistakes that occurred in achieving political reform without resorting to violence and chaos.

2. Take advantage of the Arab Spring revolutions' climate to sensitize and educate students about their rights and their appropriate duties and encourage them to participate in politics and put forward their ideas to address their issues.

3. Give students more freedom and allow them to political participation and political work within universities.

4. To include educational curricula with courses that contribute to developing political awareness and gaining political concepts among students. 
5. To conduct more research on the impact of the Arab Spring on other political concepts.

\section{References}

Abu Bakr, D. (2013). The Lean Harvest of the Arab Revolutions. International Politics Journal, (192).

Ahmad, H. (2013). Arab Spring revolutions from a regional and international perspective. Arab Affairs Magazine, (154).

Al-Arabi, S. (2012). The Media Crisis and the Emergence of a New Culture for Change. The Seventeenth Philadelphia Conference entitled Culture of Change, Philadelphia University, Amman.

Al-Azzam, A. (2003). Jordan's Attitudes Toward Political Parties. Studies Journal, 30(2).

Al-Beige, H. (1997). Political Participation and the Political Process. The Arab Future, (223).

Al-Salwi, Y. (2007). A comparative social study of electoral processes in Yemen for the period 1990-2003 (Unpublished Master Thesis).

Al-Sawaeer, S. (2017). Jordanian Foreign Policy Trends Toward the Crises of the Arab Spring between (2011-2017) (Published Master Thesis in Political Science). College of Arts, Middle East University.

Al-Shami, M. (2011). The level of political participation of Palestinian university youth in the era of globalization. Journal of the Islamic University, Gaza, 19(2).

Al-Shibli, J. (2000). Arabs and Europe: A Contemporary Political Vision. The Arab Institute for Studies and Publishing, Beirut.

Al-Sulehat, M. (2013). The implications of the Arab Spring revolutions for political awareness of Jordanian university students in the Wasat region, Al-Manara, 20(1), August 2014.

Al-Zamili, M. (2013). The Arab Spring Revolutions: Reasons and Results. Civilized Dialogue, Theme: Political Issues and Research, (4105).

Asadi, T., \& Al-Shaboot, M. (2018). Arab Spring and political transformations in the Arab region. Arab Democratic Center, Berlin, Germany.

Ayasrah, T. (2016). Main factors and sponsor of the outbreak of protests and revolutions in the Arab Spring countries. Studies of Social and Human Sciences, 43, Appendix 4.

Bradley, J. (2013). After the Arab Spring (Translated by Shaima Abdel Karim Taha, 1st ed.). Hindawi Foundation for Education and Culture, Cairo.

El-Sayed, K. (1996). The Truth of Political Pluralism in Egypt. Studies in Capitalist Transformation and Participation, p. 13.

Hamdi, A. (1993). Culture of farmers' political participation, an Egyptian field study. Center for Research and Political Studies, Faculty of Economics and Political Science, Cairo University.

Jeffrey. A., Karp, A., Susan. A., \& bBanducci, P. (2008). When politics is not Rastaman. Game: Women's Representation and Polities Engagement Electoral Studies, 227. UK: Elsevier.

Jweihat, S., \& Al-Khawaldeh, M. (2013). University Students' Attitudes Towards Political Participation in Jordan. Studies Journal, 40, Appendix 2.

Khurma et al. (2014). Social Movements in the Arab World (1st ed.). Center for Arab Unity Studies, Beirut.

Korotayev, A., Issaev, 1., Maikov, S., \& Shishkina, A. (2014). The Arab Spring: A quantitative Analysis. Arab Studies Quarterly, 36(2). https://doi.org/10.13169/arabstudquar.36.2.0149

Maatouk, N. (2012). The Impact of Political Factors on Change Movements in the Arab World 2011. Seventeenth Philadelphia Conference, entitled, Culture of Change, Philadelphia University, Amman.

Mashti, S. (2010). Political participation is based on democratic action. Journal of the Social Researcher, 9(10).

Omaima, F. (2012). Political and administrative corruption as one of the causes of the Arab revolutions. The seventeenth Philadelphia International Conference, entitled Culture of Change, Philadelphia University, Amman.

Rahma, M. (2012). The Middle East and the Arab Spring Prospects and Future. Civilized Dialogue, (3615).

Schefer, A., \& Bassiony, R. (2011). Political participation in Cairo after the January 2011 Revolution. Anthropology, 495. Cairo cultures February-June 2011. 
Serag El-Din, I. (2008). Women's Rights: Steps towards Achieving Reform. The library of Alexandrina, Alexandria

Shehata, D. (2015). The Spring Revolutions: Denial or Confirmation of the Arab Exclusion Hypothesis? Democracy Journal.

\section{Copyrights}

Copyright for this article is retained by the author(s), with first publication rights granted to the journal.

This is an open-access article distributed under the terms and conditions of the Creative Commons Attribution license (http://creativecommons.org/licenses/by/4.0/). 